\title{
A lead-width distribution for Antarctic sea ice: a case study for the Weddell Sea with high-resolution Sentinel-2 images
}

\author{
Marek Muchow ${ }^{1}$, Amelie U. Schmitt ${ }^{2}$, and Lars Kaleschke ${ }^{3}$ \\ ${ }^{1}$ Institute of Oceanography, Center for Earth System Research and Sustainability (CEN), \\ Universität Hamburg, Hamburg, Germany \\ ${ }^{2}$ Meteorological Institute, Center for Earth System Research and Sustainability (CEN), \\ Universität Hamburg, Hamburg, Germany \\ ${ }^{3}$ Alfred-Wegener-Institut, Helmholtz-Zentrum für Polar- und Meeresforschung, Bremerhaven, Germany
}

Correspondence: Marek Muchow (marek.muchow@uni-hamburg.de)

Received: 5 August 2020 - Discussion started: 18 August 2020

Revised: 22 June 2021 - Accepted: 17 August 2021 - Published: 28 September 2021

\begin{abstract}
Using Copernicus Sentinel-2 images we derive a statistical lead-width distribution for the Weddell Sea. While previous work focused on the Arctic, this is the first leadwidth distribution for Antarctic sea ice. Previous studies suggest that the lead-width distribution follows a power law with a positive exponent; however their results for the power-law exponents are not all in agreement with each other.

To detect leads we create a sea-ice surface-type classification based on 20 carefully selected cloud-free Sentinel-2 Level-1C products, which have a resolution of $10 \mathrm{~m}$. The observed time period is from November 2016 until February 2018, covering only the months from November to April. We apply two different fitting methods to the measured lead widths. The first fitting method is a linear fit, while the second method is based on a maximum likelihood approach. Here, we use both methods for the same lead-width data set to observe differences in the calculated power-law exponent.

To further investigate influences on the power-law exponent, we define two different thresholds: one for open-watercovered leads and one for open-water-covered and nilascovered leads. The influence of the lead threshold on the exponent is larger for the linear fit than for the method based on the maximum likelihood approach. We show that the exponent of the lead-width distribution ranges between 1.110 and 1.413 depending on the applied fitting method and lead threshold. This exponent for the Weddell Sea sea ice is smaller than the previously observed exponents for the Arctic sea ice.
\end{abstract}

\section{Introduction}

Leads are created by dynamic motions of the sea ice (Miles and Barry, 1998) and covered by open water or thin sea ice. They often follow a linear-like shape, can be up to tens of kilometers long and are by definition a few meters to some kilometers wide (e.g., Alam and Curry, 1997). An adequate representation of leads in climate models is important for various processes. Leads play a large role in the absorption of shortwave radiation due to the low albedo of open water and nilas, compared to the higher albedo of thicker ice and snowcovered sea ice (Perovich, 1996). Newly formed leads are also an important area for ice production and the associated brine rejection to the ocean below (Alam and Curry, 1997).

Furthermore, the heat exchange between atmosphere and ocean is strongly enhanced over leads. Using a simple heat flux model, Maykut (1978) found that the heat loss over thin ice $(0.4-0.5 \mathrm{~m})$ is 1 order of magnitude larger than over multiyear ice. In a model study, Lüpkes et al. (2008) demonstrated that an increase in the lead fraction area by $1 \%$ during the polar night can lead to local air temperature warming of up to $3.5 \mathrm{~K}$. Based on buoy data in the Weddell Sea region combined with a thermodynamic sea-ice model, Eisen and Kottmeier (2000) found that leads contribute roughly $30 \%$ to the total energy flux from the ocean to the atmosphere in winter months. Due to the large temperature differences between the air and the lead surface in winter, convective plumes forming over leads can have a large impact on the atmospheric processes in regions covered with sea ice 
(e.g., Tetzlaff et al., 2015; Lüpkes et al., 2008; Chechin et al., 2019).

Different studies suggested that the overall heat exchange over leads depends not only on lead area fraction or ice thickness but also on lead width. Using a fetch-dependent formulation of the heat exchange, Marcq and Weiss (2012) demonstrated that the heat transfer is 2 times more effective for narrow leads of several meters than for wider ones of several hundreds of meters. Furthermore, Qu et al. (2019) used a combination of remote sensing and reanalysis data and found that narrow leads $(\leq 1 \mathrm{~km})$ accounted for about a quarter of the heat flux over all leads.

To account for these lead-width-dependent processes in models, the lead width needs to be parametrized. One possibility is to apply a lead-width distribution. Several studies estimating shear and divergence rates for Arctic sea ice using satellite observations suggest that these quantities follow a power law (e.g., Marsan et al., 2004; Stern and Lindsay, 2009). Such a power-law scaling has also been found in different modeling studies (e.g., Girard et al., 2009; Wang et al., 2016; Ólason et al., 2021). Since leads are formed by divergent sea-ice motions, it is plausible to also expect a powerlaw behavior for lead width. Power-law exponents for lead widths in the Arctic have been derived from submarine measurements (Wadhams, 1981; Wadhams et al., 1985), as well as from remote sensing data from thermal imagers (Lindsay and Rothrock, 1995; Qu et al., 2019), visible imagery (Marcq and Weiss, 2012) and altimetry (Wernecke and Kaleschke, 2015). Since data with different resolutions were used in these studies, there are substantial differences in the methods used to detect leads and in the minimum lead widths considered. In addition, different statistical methods have been applied to calculate the power-law exponents. Consequently, obtained values for the power-law exponent from observations vary in absolute values and the suitable range of the distribution.

For the Antarctic, different studies have derived lead fractions (Allison et al., 1993; Reiser et al., 2020; Petty et al., 2021); however lead-width distributions have not been studied, yet. In this study, we derive a lead-width distribution for the Weddell Sea sea ice as a case study for Antarctic sea ice. For this purpose, we introduce a new method to derive lead widths using Sentinel-2 data. The main goals of this study are (1) to demonstrate that Sentinel-2 data are suitable for deriving lead widths and (2) to determine whether a powerlaw behavior - with an exponent similar to previous results for the Arctic - can also be found for Antarctic sea ice in the Weddell Sea.

The main advantage of the recently launched Sentinel-2 satellites is their high resolution up to $10 \mathrm{~m}$. This enables us to also detect very narrow leads, which most of the former studies were not capable of. We use cloud-free Sentinel2 Level-1C products, which give the top-of-the-atmosphere (TOA) reflectance (Drusch et al., 2012). The data are described in Sect. 2. Similarly to the albedo for young, thin sea ice, the TOA reflectance is related to the ice thickness. As a first step, we introduce a surface-type classification for the Sentinel-2 satellite products to identify different seaice types and leads (Sect. 3.1). The determined reflectance thresholds for leads covered with open water and nilas are then used to detect leads and calculate a lead-width distribution. Since some of the previous studies focused on leads covered only by open water and others also included leads covered by thin sea ice, we apply two different reflectance thresholds and compare the results. Subsequently, a power law is fitted to the resulting lead-width distribution. We apply two different statistical methods to determine the power-law exponents, which have both been used in different previous studies, and compare the results (Sect. 3.2). The results are presented and discussed in Sect. 4, followed by conclusions in Sect. 5.

\section{Data}

The two sun-synchronous Sentinel-2 satellites carry the passively working MultiSpectral Instrument (MSI) with 13 different spectral bands from $443 \mathrm{~nm}$ (visible) to $2190 \mathrm{~nm}$ (shortwave infrared) (ESA, 2018). The spatial resolution for the bands is 10,20 or $60 \mathrm{~m}$ while the images cover an area of $100 \times 100 \mathrm{~km}$. A higher resolution allows for the detection of narrower leads. We therefore visually compared all $10 \mathrm{~m}$ bands $(2,3,4$ and 8$)$ to identify the band with the best representation of thin ice structures. The best results were found for band $4(665 \mathrm{~nm})$, which is then used for the analysis in this study.

We selected the Weddell Sea as a case study, since Sentinel-2 is a land mission and acquires data over oceans only in the vicinity of land (Drusch et al., 2012), which restricts the regional selection. Due to the need for sunlight to capture suitable data, only Sentinel-2 Level-1C products covering the months from November to April were used. The Weddell Sea contains a large enough sea-ice cover during these months (e.g., Comiso and Nishio, 2008). Additionally, only products classified as cloud-free were selected in the Copernicus Open Access Hub (https://scihub.copernicus. eu/dhus/\#/home, last access: 22 August 2020). We noticed that in products with wide leads small clouds often occur, most likely from moisture and heat flux through the lead. Those images were rejected manually, and we only use totally cloud-free images. Thus, the final 20 Sentinel-2 Level$1 \mathrm{C}$ products are always between the months of November to April, while the whole observation period ranges from November 2016 until February 2018 (Fig. 1).

The lead-width detection method (Sect. 3.2) is applied to all 20 products. The classification of surface types and threshold identification (Sect. 3.1) is based on 9 of those 20 products from January to April 2017. For more details on the data see Table 1 . 


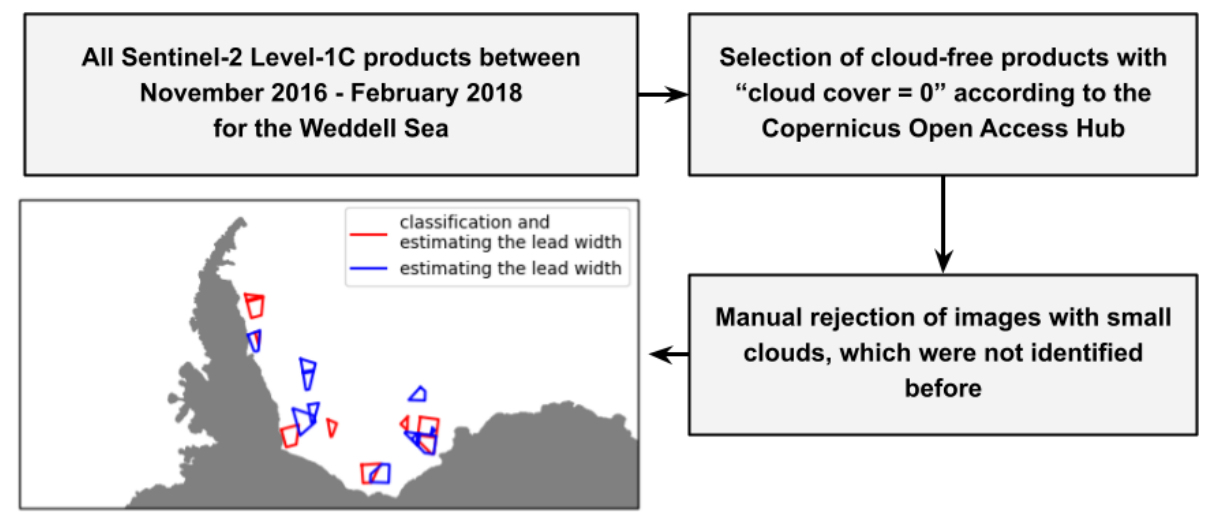

Figure 1. Display of the selection steps for the 20 Sentinel-2 Level-1C products. The location of the 20 different Sentinel-2 Level-1C products for this study is the Weddell Sea. Of the 20 products, 9 were used for the sea-ice surface-type classification (red border), while for the lead-width detection all 20 were used (red and blue border). For the border of the product the "real image outlines" are displayed, which are not always rectangular since the satellite swath does not always overlap completely with the processing grid applied by ESA. Displayed in gray is the Antarctic continent border including the shelf ice border measured with different satellite radar from 2007-2009 (Mouginot et al., 2017; Rignot et al., 2013).

Table 1. Sentinel-2 Level-1C products used for measuring the lead width. Products which are also used for the classification are labeled with "yes".

\begin{tabular}{|c|c|c|}
\hline Sensing date (dd/mm/yyyy) & Classification & Product name \\
\hline $12 / 11 / 2016$ & no & S2A_MSIL1C_20161112T104212_N0204_R122_T26CMC_20161112T104210 \\
\hline 20/11/2016 & no & S2A_MSIL1C_20161120T100152_N0204_R093_T25CES_20161120T100153 \\
\hline 20/11/2016 & no & S2A_MSIL1C_20161120T100152_N0204_R093_T25CDS_20161120T100153 \\
\hline 29/11/2016 & no & S2A_MSIL1C_20161129T103152_N0204_R079_T24CXE_20161129T103151 \\
\hline 20/12/2016 & no & S2A_MSIL1C_20161220T100052_N0204_R093_T24CVV_20161220T100049 \\
\hline 23/02/2017 & yes & S2A_MSIL1C_20170223T123141_N0204_R023_T21CVT_20170223T123144 \\
\hline 23/02/2017 & no & S2A_MSIL1C_20170223T123141_N0204_R023_T22DDF_20170223T123144 \\
\hline 23/02/2017 & no & S2A_MSIL1C_20170223T123141_N0204_R023_T22DDG_20170223T123144 \\
\hline 24/02/2017 & yes & S2A_MSIL1C_20170224T120231_N0204_R037_T22CEC_20170224T120234 \\
\hline 26/02/2017 & yes & S2A_MSIL1C_20170226T110241_N0204_R065_T23CNQ_20170226T110244 \\
\hline 02/03/2017 & no & S2A_MSIL1C_20170302T122211_N0204_R123_T22CDD_20170302T122205 \\
\hline 13/03/2017 & no & S2A_MSIL1C_20170313T101141_N0204_R136_T25CDS_20170313T101144 \\
\hline 16/03/2017 & yes & S2A_MSIL1C_20170316T102141_N0204_R036_T25CES_20170316T102141 \\
\hline 16/03/2017 & yes & S2A_MSIL1C_20170316T102141_N0204_R036_T25CES_20170316T102141 \\
\hline 16/03/2017 & yes & S2A_MSIL1C_20170316T102141_N0204_R036_T24CWC_20170316T102141 \\
\hline 06/04/2017 & yes & S2A_MSIL1C_20170406T131051_N0204_R052_T21DVF_20170406T131050 \\
\hline 06/04/2017 & yes & S2A_MSIL1C_20170406T131051_N0204_R052_T21DVG_20170406T131050 \\
\hline 06/04/2017 & yes & S2A_MSIL1C_20170406T131051_N0204_R052_T21DVD_20170406T131050 \\
\hline 06/04/2017 & no & S2A_MSIL1C_20170406T131051_N0204_R052_T20DPJ_20170406T131050 \\
\hline 09/02/2018 & no & S2A_MSIL1C_20180209T120241_N0206_R037_T21CWU_20180209T163245 \\
\hline
\end{tabular}

\section{Methods}

\subsection{Threshold identification}

The threshold identification contains the following main steps (Fig. 2): first, five different surface types are classified based on the top-of-the-atmosphere (TOA) reflectance. Second, a TOA reflectance probability data set for each sur- face type is created and the Gaussian curves are fitted to each data set. Third, the results from the surface classification are used to identify two thresholds, which are later used for creating binary "lead-sea-ice" images for the lead-width measurement.

For the surface-type classification 9 out of 20 later-used Sentinel-2 Level-1C products are utilized (Sect. 2). We iden- 


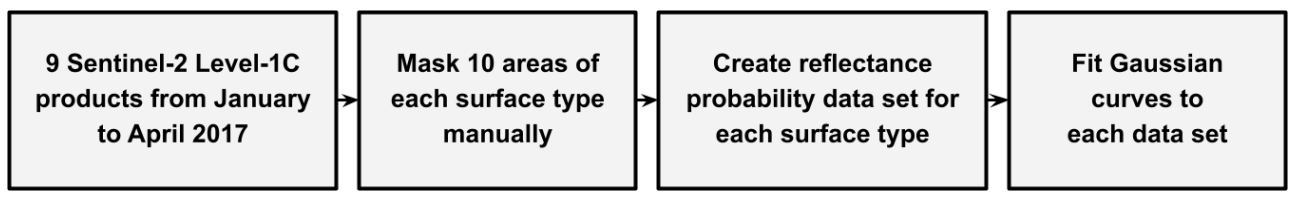

Figure 2. Data analysis steps for obtaining the Gaussian curves for each surface type.

tify five different surface types including open water and four different ice types (nilas, gray sea ice, gray-white sea ice and sea ice covered with snow). The names of the seaice categories are based on the WMO Sea-Ice Nomenclature (WMO, 2014) for consistency with other literature. However, we want to stress that our classification is based on the TOA reflectance and not on sea-ice age or thickness. On every band-4 image, 10 areas of each surface type are masked manually. Thereafter, the TOA reflectance of each pixel within the mask is used to create a reflectance value data set for each surface type. The reflectance values lie between zero and 1 .

To analyze the range of the TOA reflectance for each surface type, histograms are created, which show the occurrence of pixels with a specific TOA reflectance. These histograms are used to fit a summation over Gaussian functions with the mean $\mu$ and standard deviation $\sigma$ to the data:

$y(x)=\sum_{i=1}^{n} a_{i} \cdot \frac{1}{\sqrt{2 \pi} \sigma_{i}} \cdot e^{-0.5\left(\frac{x-\mu_{i}}{\sigma_{i}}\right)^{2}}$.

$n$ indicates the number of Gaussian curves that were combined into one function and weighted with the weighting parameter $a_{i}$, for fitting the histograms. By using $n>1$ we can account for multiple maxima in a distribution. Thus, $n=2$ is used for gray-white sea ice and $n=3$ for gray sea ice (Fig. 3). One Gaussian curve $(n=1)$ is fitted to the histogram for open water, nilas and sea ice covered with snow.

The threshold for each surface category is then determined as the values of the TOA reflectance at the point of intersection of two curves adjacent to each other. An exception is the threshold for open water, where two points of intersection occur. In this case the second point of intersection is chosen to be the threshold because the first point of intersection is before the maximum. The area of intersection of two curves is then the overlap error of those thresholds and describes where we manually classified pixels with the same TOA reflectance in different sea-ice surface categories.

For the lead identification two different thresholds are used to create binary images: one for leads covered with open water (OW threshold) and one for leads covered with open water and nilas (OWN threshold). We decided to use two thresholds to observe the effect of the coverage of the lead on the power law similarly to Marcq and Weiss (2012), who used two different luminance thresholds for leads. Additionally, we decided to use the combined OWN threshold since open water refreezes quickly in leads depending on the surrounding temperatures, but the leads keep similar properties in regards to heat exchange to open-water leads. Additionally, leads are defined as being navigable by surface vessels (WMO, 2014), which is still true for leads covered with nilas.

\subsection{Measuring the apparent lead width and determining the power-law exponent}

Since the leads within each image can have arbitrary orientations, it is not guaranteed that the "true lead width" orthogonally to the leads' orientation is measured but the width of a line across the lead at an angle other then $90^{\circ}$. As in Wernecke and Kaleschke (2015) we call the measured lead width the apparent lead width as a proxy for the true lead width. To measure the apparent lead width we use a measurement grid consisting of 10 vertical and 10 horizontal equally spaced measurement tracks across each Sentinel-2 product (Fig. 4).

The obtained data set of apparent lead widths can then be displayed as a histogram showing the occurrence $p(x)$ for each specific width. As has been carried out in previous studies (Wadhams, 1981; Wadhams et al., 1985; Lindsay and Rothrock, 1995; Marcq and Weiss, 2012; Wernecke and Kaleschke, 2015; Qu et al., 2019), we assume that the shape of the histogram follows a power law with the exponent $\alpha$ and the apparent lead widths $x_{\text {width }}$ :

$p(x)=C \cdot x_{\text {width }}^{-\alpha}$.

The scaling parameter $C$ is the offset at the $y$ axis and therefore related to the number of measurements, and it is not further investigated here.

We apply two different methods to estimate the power-law exponent $\alpha$. For the linear fit (LF method) the apparent lead widths are sorted by size so that the frequency $p(x)$ of the specific width is available. On a plot with both logarithmic axes, the distribution of the data follows a straight line with a specific slope and an axis intercept. The slope is the representation of the power-law exponent $\alpha$. Due to the same influence of every value for the result of the fit, atypical values have a strong effect on the result (Berk, 2004).

The second method for estimating the exponent $\alpha$ is the method for discrete values by Clauset et al. (2009), which is based on a maximum likelihood approach (ML method). The power-law distribution diverges at zero; therefore a lower boundary $x_{\min }>0$ is needed. In this study, $x_{\min }$ is the smallest possible apparent lead width, which is the image resolution of $10 \mathrm{~m}$. The following equation is used for estimating 


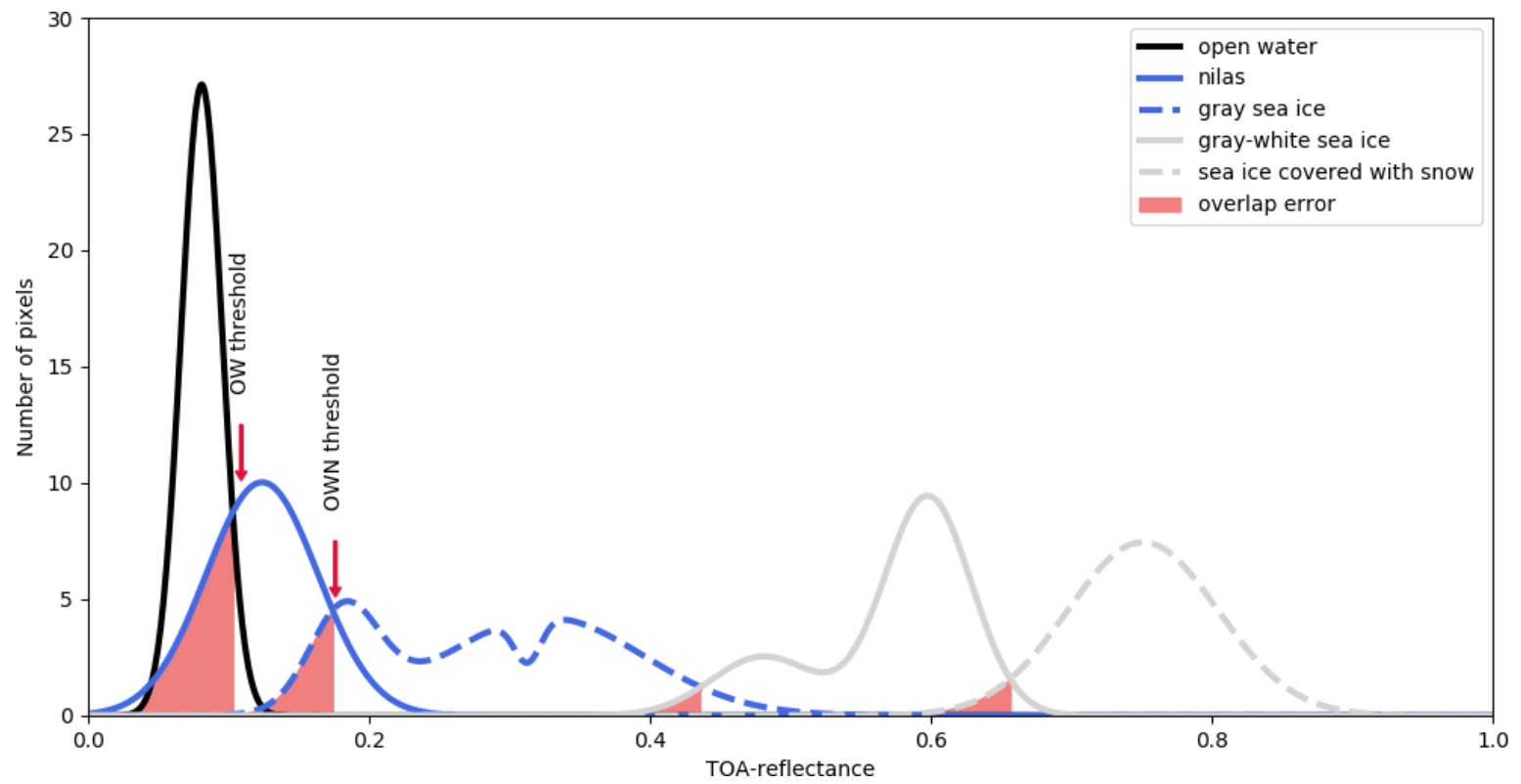

Figure 3. The number of pixels within every surface type for a specific TOA reflectance. The TOA reflectance threshold for each surface type is the point of intersection of two curves adjacent to each other. The error is shown as the overlap error of these two curves below each threshold. The red arrows show the two thresholds later used for the lead identification for the lead-width measurement: the open-water (OW) threshold and the open-water-and-nilas (OWN) threshold.

(a) original band 4 image

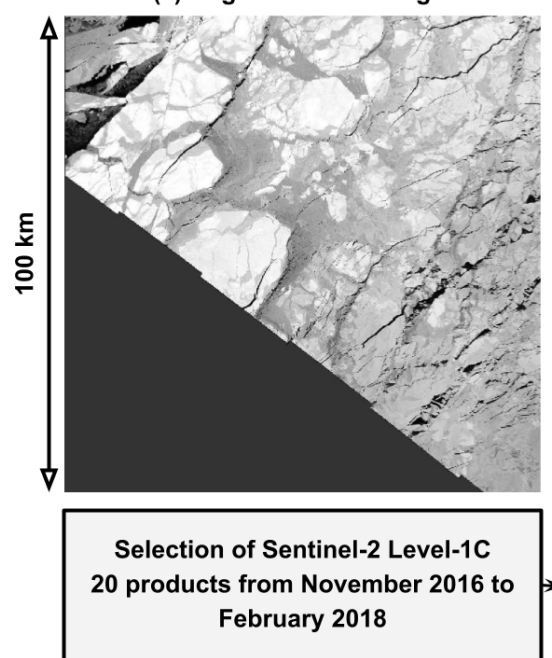

(b) open water and nilas (OWN) threshold

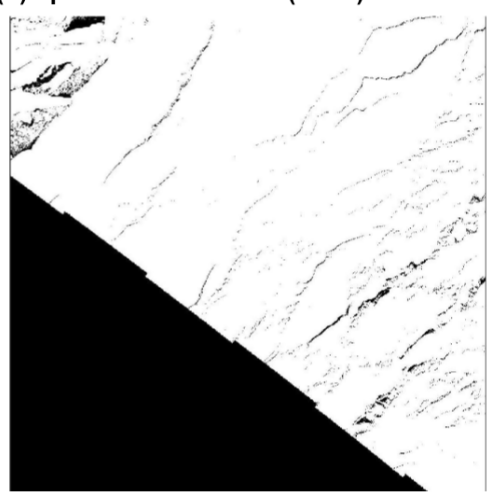

Convert to binary image using "open water" or "open water and nilas" threshold (c) lead-width measurement

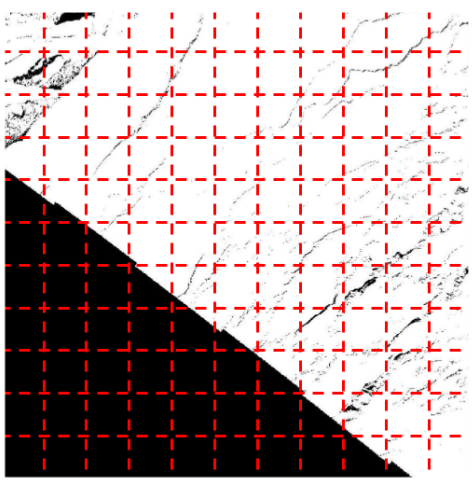

Measuring the lead width along ten horizontal and ten vertical measurement tracks

Figure 4. (a) Exemplary original Sentinel-2 Level-1C band-4 image (sensing date: 16 March 2017). (b) Binary image after the application of the open-water-and-nilas (OWN) threshold, where leads are indicated with black pixels and no leads with white ones. (c) Applied measurement grid with 10 horizontal and vertical measurement tracks. The swath of the Sentinel-2 satellite does not cover the whole image area defined by the ESA data-processing grid. Thus, only the area covered by the satellite swath is considered for the lead-width measurement.

the power-law exponent $\alpha$ :

$\alpha \approx 1+n \cdot\left[\sum_{i=1}^{n} \ln \left(\frac{x_{\text {width }, i}}{x_{\min }-\frac{1}{2} \cdot \text { step size }}\right)\right]^{-1}$.

The total number of counted leads is $n$, and $x_{\text {width, } i}$ is the measured lead widths. Since the data are discrete with a res- olution of $10 \mathrm{~m}$, the "step size" in Eq. (3) is set to $10 \mathrm{~m}$ similarly to in Wernecke and Kaleschke (2015).

To reduce the influence of possible single outlying measurements on the result of the power-law exponent, we estimated the lead-width distribution 100 times with a random selection of $70 \%$ of the measured apparent lead widths. We choose $70 \%$ to still have enough measured widths while hav- 
Table 2. The table displays the threshold for each surface type from the surface classification. The thresholds are the point of intersection between the Gaussian curves describing the TOA reflectance values that occurred for each surface type (Fig. 3, Sect. 3.1). Every threshold contains the surface types that are above it in the table. Sea ice covered with snow has no estimated threshold; therefore it is indicated as 1.0 .

\begin{tabular}{lrr}
\hline Surface type & $\begin{array}{r}\text { Threshold (TOA } \\
\text { reflectance) }\end{array}$ & $\begin{array}{r}\text { Overlap } \\
\text { error (\%) }\end{array}$ \\
\hline Open water & 0.10 & 29 \\
\hline Nilas & 0.17 & 11 \\
\hline Gray sea ice & 0.44 & 3 \\
\hline Gray-white sea ice & & \\
& 0.66 & 4 \\
\hline Sea ice covered with snow & 1.0 & \\
\hline
\end{tabular}

ing variation between the data sets. The final power-law exponent is then estimated as the mean over the 100 calculations. Additionally, as a measure for uncertainty, the standard deviation is also estimated from the 100 calculations.

\section{Results and discussion}

\subsection{Threshold identification}

The thresholds between surface categories and corresponding overlap errors are determined using the method described in Sect. 3.1. With Sentinel-2 band-4 images it is possible to distinguish between five different surface types (open water, nilas, gray sea ice, gray-white sea ice, sea ice covered with snow) based on top-of-the-atmosphere (TOA) reflectance values (Fig. 3). The results for the thresholds and the corresponding overlap error are presented in Table 2. Note that for the lead identification only two thresholds are applied: the open-water (OW) threshold and a threshold combining open water and nilas (OWN).

The common value used to compare optical properties of sea ice is the albedo. In this study, we measure TOA reflectance instead of albedo. Both properties increase with the sea ice and snow cover thickness, especially for young, thin sea ice in the absence of melting processes. In addition to this, we only use cloud-free Sentinel-2 band- 4 images. Thus, the atmosphere has a negligible influence on the reflectance measurement. We estimated the thresholds with Sentinel-2 band-4 images from January to April 2017 to include different sun and look angles. Before estimating the thresholds we also compared the TOA reflectance values for each surface type within the products with each other and found no sig- nificant difference. To evaluate the two thresholds, which are later used for the lead detection, they are compared to measured albedo values from the East Antarctic sea-ice zone in austral spring and summer by Brandt et al. (2005). Their estimated albedos for open water (0.07) and nilas without snow cover $(0.14)$ are close to the thresholds estimated here for the same surface types. For the classification of the two laterused thresholds we aimed to classify structures without snow cover. For the other surface types it is much more difficult to make assumptions about the snow cover or thickness due to the fact that only the reflectance values are known. Nevertheless, our estimated TOA reflectance thresholds for each surface type are always in the range of the reference albedo measurements from Brandt et al. (2005).

Additionally, since leads normally have sharp edges the selection of areas as example values for open water and nilas was comparatively easy compared to the other sea-ice surface types. The thicker the ice and snow cover, the more unreliable these observations become. To obtain a more precise classification of the surface types' validation with other data sources like field measurements could be beneficial. Nevertheless, the TOA reflectance thresholds $(0.10$ for OW and 0.16 for OWN) were used for the lead detection and agree with values from previous measurements (Brandt et al., 2005).

\subsection{Measured lead widths and the power-law exponent}

The lead-width distribution derived from 20 Sentinel-2 products using both the open-water (OW) and the open-waterand-nilas (OWN) threshold is presented in Fig. 5. The total number of leads observed with the OW threshold is 2024, while for the OWN threshold 3799 leads are observed. The largest observed apparent lead widths are $6500 \mathrm{~m}$ for the OW threshold and $6530 \mathrm{~m}$ for the OWN threshold. Looking at the distribution of the measured lead widths, it is evident that the small leads dominate and that with an increasing width the number of leads decreases. We measured leads with a width from $10 \mathrm{~m}$ down to the resolution of the Sentinel-2 band-4 image resolution and upwards, but the number of measured leads with a width of $10 \mathrm{~m}$ is lower than what might be expected (Figs. 5 and 6). One possible reason is the resolution itself, and according to Wernecke and Kaleschke (2015) this is a typical feature with fewer measurements for the lower bound of the resolution, since a $10 \mathrm{~m}$ lead is not always covered completely by 1 image pixel but partially by 2 or more, so the signal of the lead is not detected. The upper limit of the power-law range is cut off by the availability of wider leads, since wider leads tend to produce small clouds and we only analyzed cloud-free data.

As described in Sect. 3.2 we apply two different methods to fit a power law to the lead-width distribution. The calculated power-law exponents for both thresholds and fitting methods are presented at the bottom of Table 3. At first we compare the results for the same thresholds with different methods to one another (Fig. 5) to estimate the impact of 
(a) OW threshold

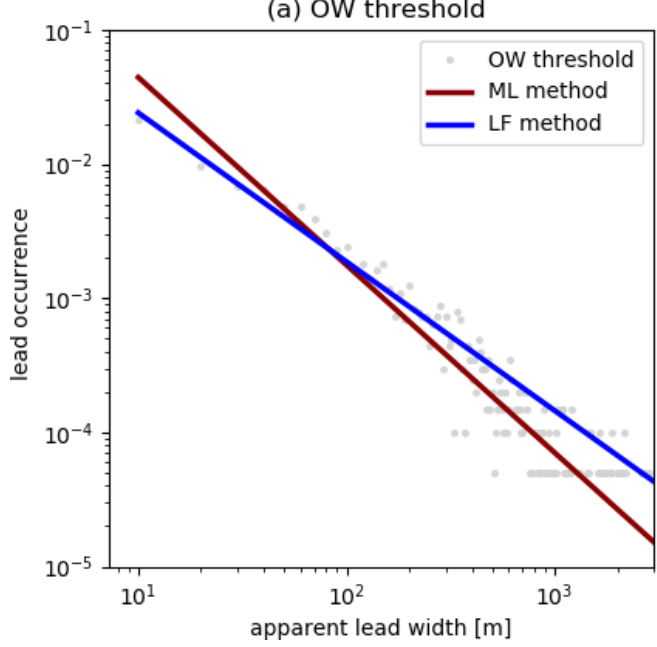

(b) OWN threshold

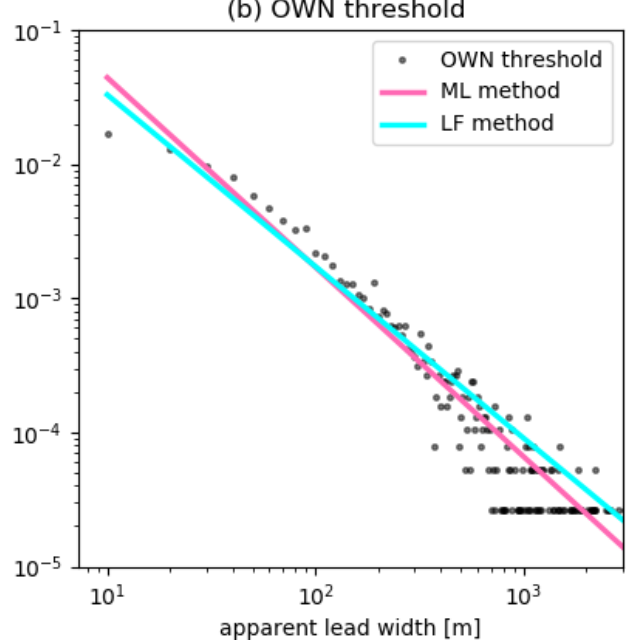

Figure 5. Relative lead occurrence as a function of measured lead width (dots). Lead widths were measured using (a) the open-water (OW) threshold and (b) the open-water-and-nilas (OWN) threshold. Straight lines indicate the fitted power-law curves using the ML and LF method.

(a) ML method

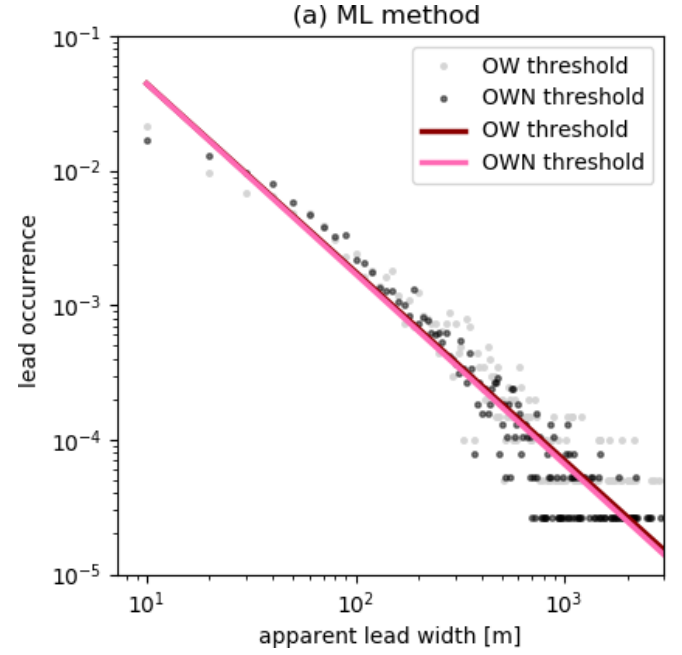

(b) LF method

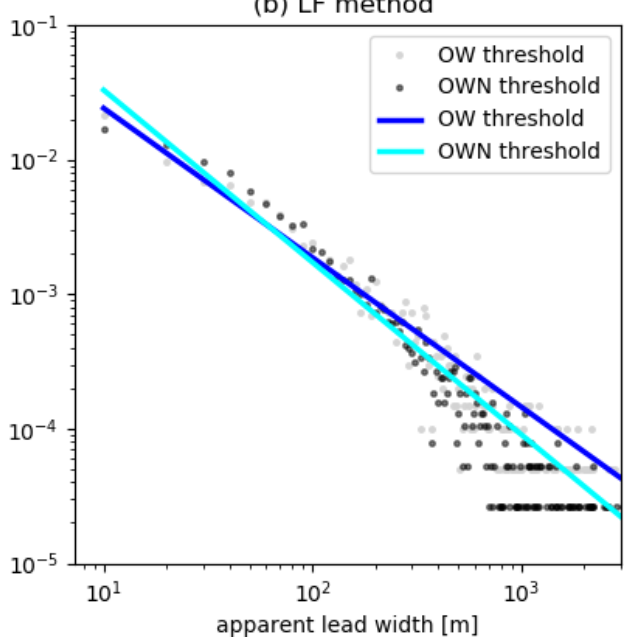

Figure 6. Same as Fig. 5 but with the results for both thresholds for (a) the ML fitting method and (b) the LF fitting method.

the methods. The values for the power-law exponent with the OW threshold are 1.110 (LF method) and 1.399 (ML method). For this threshold, the method has a strong impact on the result. For the OWN threshold the results are closer (LF method, 1.280; ML method, 1.413). The standard deviation for the LF method is 10 times higher (0.02) than for the ML method (0.002). These results confirm that the method has a non-neglectable effect on the result of the exponent for the sea-ice width distribution power law.

Secondly, we compare the results for the same method with both thresholds to show the importance of the choice of thresholds (Fig. 6). The OW threshold covers only leads without any thin sea ice, while the OWN threshold includes open water but also leads covered with sea ice. Thus, the OWN threshold data set includes more lead-width measurements but also wider leads due to lead edges covered with nilas. For the LF method the different thresholds give two different results of the exponent for the lead-width distribution power law (OW, 1.110; OWN, 1.280). Otherwise, for the ML method the choice of the threshold has no strong influence on the result of the power-law exponent (OW, 1.399; OWN, 1.413). Thus, choosing different thresholds or criteria for the definition of the lead can influence the result. This is supported by the result of Marcq and Weiss (2012), who used two differing thresholds which have a similar range to one another, as with our estimates for the LF method (Table 3).

Previous studies about lead-width distributions (Table 3) focused on different regions in the Arctic and not on Antarctic regions. While observing leads in the Arctic sea ice is outside the scope of this study, we compare our results with the results from the Arctic sea ice to gain more insight about possible effects on the differences. The exponent of the lead- 
Table 3. Different results from the literature and this study for the Weddell Sea sorted by publishing date. The threshold definition for lead identification differs between the studies. Marcq and Weiss (2012) use two different luminance thresholds. The last two entries are the results of this study for the Weddell Sea for which two thresholds (OW, open-water-covered leads; OWN, open-water-covered and nilas-covered leads) are also applied. The LF method stands for a linear fit, and the ML method stays for the method after Clauset et al. (2009). A detailed explanation of the methods is in Sect. 3.2.

\begin{tabular}{|c|c|c|c|c|c|c|}
\hline Source & $\begin{array}{l}\text { Fitting } \\
\text { method }\end{array}$ & $\begin{array}{l}\text { Platform/ } \\
\text { instrument }\end{array}$ & Time and region & $\begin{array}{l}\text { Resolution of } \\
\text { the power law }\end{array}$ & $\begin{array}{l}\text { Range of the } \\
\text { power law }\end{array}$ & $\begin{array}{l}\text { Power-law exponent } \\
\alpha\end{array}$ \\
\hline Wadhams (1981) & $\mathrm{LF}$ & $\begin{array}{l}\text { submarine } \\
\text { mission }\end{array}$ & $\begin{array}{l}\text { October 1976, Euro- } \\
\text { pean Arctic Ocean }\end{array}$ & about $5 \mathrm{~m}$ & $50-1000 \mathrm{~m}$ & 2.00 \\
\hline Wadhams et al. (1985) & $\mathrm{LF}$ & $\begin{array}{l}\text { submarine } \\
\text { mission }\end{array}$ & $\begin{array}{l}\text { February } 1967, \\
\text { Davis Strait }\end{array}$ & about $5 \mathrm{~m}$ & $50-1000 \mathrm{~m}$ & 2.29 \\
\hline $\begin{array}{l}\text { Lindsay and Rothrock } \\
\text { (1995) }\end{array}$ & $\mathrm{LF}$ & AVHRR & $\begin{array}{l}\text { 1989, central Arctic } \\
\text { Ocean }\end{array}$ & $1 \mathrm{~km}$ & $1-50 \mathrm{~km}$ & $1.60 \pm 0.18$ \\
\hline Marcq and Weiss (2012) & ML & SPOT & $\begin{array}{l}\text { April 1996, central } \\
\text { Arctic Ocean }\end{array}$ & $10 \mathrm{~m}$ & $0.02-2 \mathrm{~km}$ & $\begin{array}{l}2.1-2.3 \\
2.5-2.6\end{array}$ \\
\hline $\begin{array}{l}\text { Wernecke and Kaleschke } \\
(2015)\end{array}$ & ML & CryoSat-2 & $\begin{array}{l}\text { winter 2011-2014, } \\
\text { Arctic Ocean }\end{array}$ & $300 \mathrm{~m}$ & $\geq 600 \mathrm{~m}$ & $2.47 \pm 0.04$ \\
\hline Qu et al. (2019) & $\mathrm{LF}$ & $\begin{array}{l}\text { MODIS, } \\
\text { Landsat } 8\end{array}$ & $\begin{array}{l}\text { April 2015, Beaufort } \\
\text { Sea }\end{array}$ & $30 \mathrm{~m}-1 \mathrm{~km}$ & $\geq 30 \mathrm{~m}$ & $2.241-2.346$ \\
\hline This study & $\mathrm{LF}$ & Sentinel-2 & $\begin{array}{l}\text { 2016-2018 } \\
\text { (November-April), } \\
\text { Weddell Sea }\end{array}$ & $10 \mathrm{~m}$ & $0.01-6.5 \mathrm{~km}$ & $\begin{array}{l}\text { OW: } 1.110 \pm 0.020 \\
\text { OWN: } 1.280 \pm 0.020\end{array}$ \\
\hline This study & ML & Sentinel-2 & $\begin{array}{l}\text { 2016-2018 } \\
\text { (November-April), } \\
\text { Weddell Sea }\end{array}$ & $10 \mathrm{~m}$ & $0.01-6.5 \mathrm{~km}$ & $\begin{array}{l}\text { OW: } 1.399 \pm 0.002 \\
\text { OWN: } 1.413 \pm 0.002\end{array}$ \\
\hline
\end{tabular}

width distribution power law determined by this study for the Weddell Sea sea ice is smaller than in all previous studies for Arctic sea ice: the results by Wernecke and Kaleschke (2015) using the CryoSat-2 satellite support the earlier-mentioned results by Marcq and Weiss (2012) (SPOT satellite) with a power-law exponent of around 2.50. The power-law exponent found by Qu et al. (2019) (2.241-2.346) using a combination of MODIS and Landsat 8 is in the same range as the first and lower exponent from Marcq and Weiss (2012), who also used two thresholds. Furthermore, there were two surveys using submarines from which power-law exponents of 2.00 and 2.29 were calculated (Wadhams, 1981; Wadhams et al., 1985). The only result below 2.0 is from Lindsay and Rothrock (1995) with a power-law exponent of 1.60. They used data from the Advanced Very High Resolution Radiometer (AVHRR).

In addition to the different measurement systems (different satellites and submarines) and different methods regarding lead definition and measurement, the studies for the Arctic observe leads in different regions (Table 3). Willmes and Heinemann (2016) showed that the sea-ice wintertime lead frequencies differ throughout the Arctic Ocean and identified the marginal ice zone in the Fram Strait and the Barents Sea as the primary region for lead activities. Lead fre- quency distributions in the pan-Arctic indicate an influence of bathymetry and ocean currents. However, the result for the lead-width distribution by Lindsay and Rothrock (1995) also disagrees with the result from Marcq and Weiss (2012), both of which were obtained in the central Arctic Ocean, while other previous results are similar (Marcq and Weiss, 2012; Wernecke and Kaleschke, 2015; Qu et al., 2019).

Furthermore, the results for the power-law exponent displayed in Table 3 are based on a scale-invariant approach; however $\mathrm{Qu}$ et al. (2019) used different resolutions of the measured lead width ranging from $30 \mathrm{~m}$ to $1 \mathrm{~km}$ resulting in differences in the power-law exponent in the first decimal place, indicating that the power-law scaling for lead width might not always be scale invariant. In addition to that, Rampal et al. (2019) confirmed a multi-fractal dependence of the sea-ice deformation rates on timescales and space scales. Thus, applying these results to different processes related to deformation, like leads formed due to divergence, would be a necessary step for further research.

Another possible reason for the differences is the different conditions in both regions. While the Arctic Ocean is surrounded by land mass, the Southern Ocean surrounds the Antarctic continent. The Antarctic sea ice is exposed to the Antarctic Circumpolar Current and strong circumpo- 
lar winds. The Antarctic sea-ice cover is generally more divergent than much of the Arctic ice cover (Gloersen et al., 1993). Lead fractions in the central Arctic shown by Petty et al. (2021) are lower compared to in the Southern Ocean, which also shows some regional differences. Additionally, Worby et al. (2008) estimated the long-term mean (19812005) of total Antarctic sea-ice thickness in winter as $0.66 \pm$ $0.60 \mathrm{~m}$. For the Arctic Ocean, Kwok et al. (2009) calculated a 5-year mean (2003-2008) ice thickness during winter of $2.9 \pm 0.3 \mathrm{~m}$. Different sea-ice thicknesses influence the sea ice to have different rheologic properties (Feltham, 2008).

\section{Conclusions}

We introduce a lead-width distribution for Antarctic sea ice using the Weddell Sea as a case study. To observe leads and their width with Sentinel-2 Level-1C products, it is necessary to have a surface-type classification. Therefore we analyzed Sentinel-2 Level-1C products (band 4, $665 \mathrm{~nm}$ ) with a resolution of $10 \mathrm{~m}$ and created a surface-type classification based on the top-of-the-atmosphere (TOA) reflectance. With this classification the Sentinel-2 Level-1C data can be used to detect and observe sea-ice leads under cloud-free conditions with a resolution of $10 \mathrm{~m}$. The local overpass time of the two Sentinel-2 satellites matches the SPOT satellite and is close to Landsat 8 , which provides the possibility for a future combination of the data sets to form longer time series. The mission lifetime for Sentinel-2 satellites, which were launched in 2015 and 2017, is planned to be 15 years (Drusch et al., 2012).

We apply two different fitting methods, which have been used in previous studies for Arctic sea ice (Wadhams, 1981; Wadhams et al., 1985; Lindsay and Rothrock, 1995; Marcq and Weiss, 2012; Wernecke and Kaleschke, 2015), to the measured lead widths. The first fitting method is a linear fit (LF method), while the second method is based on a maximum likelihood approach by Clauset et al. (2009) (ML method). To further investigate influences on the power-law exponent, we define two different lead thresholds: OW for open-water-covered leads and OWN for open-water-covered and nilas-covered leads. We confirm that the lead-width distribution for Weddell Sea sea ice follows a power law, showing similar behavior to the lead-width distribution in the Arctic but with a smaller exponent. We also demonstrate that the fitting method has an influence on the result of the exponent, and for further investigations, established methods should be applied to guarantee comparability of the results. With the LF method the power-law exponent for the lead-width distribution is $1.110-1.280$ including both thresholds, while the exponent with the ML method shows less dependence on the threshold and is 1.399-1.413.

Thus, it is necessary to carry out further research on leads in the Southern Ocean to fully understand differences and similarities between the Arctic and Antarctic sea ice and account for possible regional differences in lead widths throughout the Antarctic sea ice. For future comparison the same fitting method should be applied, since our study shows that with the same data different results occur.

Data availability. All Sentinel-2 Level-1C products used are given in Table 1. We accessed the data using the Copernicus Open Access Hub (2018, https://scihub.copernicus.eu/dhus/\#/home).

Author contributions. MM acquired and checked the data, created the surface-type classification, and derived the lead-width distribution under the supervision of LK. AUS helped with the derivation of the lead-width distribution and editing the paper. MM prepared the paper with contributions of all co-authors.

Competing interests. The authors declare that they have no conflict of interest.

Disclaimer. Publisher's note: Copernicus Publications remains neutral with regard to jurisdictional claims in published maps and institutional affiliations.

Acknowledgements. This work was financially supported by the German Science Foundation (DFG) with the project number 314651818, and the publication was supported by Johanna Baehr from the Institute of Oceanography, Universität Hamburg. The authors acknowledge the Copernicus program and the European Space Agency (ESA) for providing the imagery data for the Sentinel-2 satellites with the Copernicus Open Access Hub.

We thank the editors Yevgeny Aksenov and Jennifer Hutchings and the two anonymous referees for their helpful criticism.

Financial support. This work was financially supported by the German Science Foundation (DFG) with the project number 314651818, and the publication was supported by Johanna Baehr from the Institute of Oceanography, Universität Hamburg.

Review statement. This paper was edited by Yevgeny Aksenov and Jennifer Hutchings and reviewed by two anonymous referees.

\section{References}

Alam, A. and Curry, J. A.: Determination of surface turbulent fluxes over leads in Arctic sea ice, J. Geophys. Res.-Oceans, 102, 33313343, https://doi.org/10.1029/96JC03606, 1997.

Allison, I., Brandt, R. E., and Warren, S. G.: East Antarctic sea ice: Albedo, thickness distribution, and snow cover, J. Geophys. Res.Oceans, 98, 12417-12429, https://doi.org/10.1029/93JC00648, 1993. 
Berk, R. A.: Regression analysis: A constructive critique, vol. 11, Sage, United States of America, https://doi.org/10.4135/9781483348834, 2004.

Brandt, R. E., Warren, S. G., Worby, A. P., and Grenfell, T. C.: Surface albedo of the Antarctic sea ice zone, J. Climate, 18, 36063622, https://doi.org/10.1175/JCLI3489.1, 2005.

Chechin, D. G., Makhotina, I. A., Lüpkes, C., and Makshtas, A. P.: Effect of wind speed and leads on clear-sky cooling over Arctic sea ice during polar night, J. Atmos. Sci., 76, 2481-2503, https://doi.org/10.1175/JAS-D-18-0277.1, 2019.

Clauset, A., Shalizi, C. R., and Newman, M. E.: Power-law distributions in empirical data, SIAM Rev., 51, 661-703, https://doi.org/10.1137/070710111, 2009.

Comiso, J. C. and Nishio, F.: Trends in the sea ice cover using enhanced and compatible AMSR-E, SSM/I, and SMMR data, J. Geophys. Res.-Oceans, 113, C02S07, https://doi.org/10.1029/2007JC004257, 2008.

Copernicus Open Access Hub: https://scihub.copernicus.eu/dhus/\#/ home, last access: 15 June 2018.

Drusch, M., Del Bello, U., Carlier, S., Colin, O., Fernandez, V., Gascon, F., Hoersch, B., Isola, C., Laberinti, P., Martimort, P., Meygret, A., Spoto, F., Sy, O., Marchese, F., and Bargellini, P.: Sentinel-2: ESA's optical high-resolution mission for GMES operational services, Remote Sens. Environ., 120, 2536, https://doi.org/10.1016/j.rse.2011.11.026, 2012.

Eisen, O. and Kottmeier, C.: On the importance of leads in sea ice to the energy balance and ice formation in the Weddell Sea, J. Geophys. Res.-Oceans, 105, 14045-14060, https://doi.org/10.1029/2000JC900050, 2000.

ESA: sentinel online, available at: https://earth.esa.int/web/ sentinel/user-guides/sentinel-2-msi/resolutions/spatial (last access: 19 August 2019), 2018.

Feltham, D. L.: Sea ice rheology, Annu. Rev. Fluid Mech., 40, 91112, https://doi.org/10.1146/annurev.fluid.40.111406.102151, 2008.

Girard, L., Weiss, J., Molines, J.-M., Barnier, B., and Bouillon, S.: Evaluation of high-resolution sea ice models on the basis of statistical and scaling properties of Arctic sea ice drift and deformation, J. Geophys. Res.-Oceans, 114, C08015. https://doi.org/10.1029/2008JC005182, 2009.

Gloersen, P., Campbell, W. J., Cavalieri, D. J., Comiso, J. C., Parkinson, C. L., and Zwally, H. J.: Satellite passive microwave observations and analysis of Arctic and Antarctic sea ice, 1978-1987, Ann. Glaciol., 17, 149-154, https://doi.org/10.3189/S0260305500012751, 1993.

Kwok, R., Cunningham, G., Wensnahan, M., Rigor, I., Zwally, H., and Yi, D.: Thinning and volume loss of the Arctic Ocean sea ice cover: 2003-2008, J. Geophys. Res.-Oceans, 114, C07005, https://doi.org/10.1029/2009JC005312, 2009.

Lindsay, R. and Rothrock, D.: Arctic sea ice leads from advanced very high resolution radiometer images, J. Geophys. Res.Oceans, 100, 4533-4544, https://doi.org/10.1029/94JC02393, 1995.

Lüpkes, C., Vihma, T., Birnbaum, G., and Wacker, U.: Influence of leads in sea ice on the temperature of the atmospheric boundary layer during polar night, Geophys. Res. Lett., 35, L03805, https://doi.org/10.1029/2007GL032461, 2008.

Marcq, S. and Weiss, J.: Influence of sea ice lead-width distribution on turbulent heat transfer between the ocean and the atmo- sphere, The Cryosphere, 6, 143-156, https://doi.org/10.5194/tc6-143-2012, 2012.

Marsan, D., Stern, H., Lindsay, R., and Weiss, J.: Scale dependence and localization of the deformation of Arctic sea ice, Phys. Rev. Lett., 93, 178501, https://doi.org/10.1103/PhysRevLett.93.178501, 2004.

Maykut, G. A.: Energy exchange over young sea ice in the central Arctic, J. Geophys. Res.-Oceans, 83, 3646-3658, https://doi.org/10.1029/JC083iC07p03646, 1978.

Miles, M. W. and Barry, R. G.: A 5-year satellite climatology of winter sea ice leads in the western Arctic, J. Geophys. Res.Oceans, 103, 21723-21734, https://doi.org/10.1029/98JC01997, 1998.

Mouginot, J., Scheuchl, B., and Rignot, E.: MEaSUREs Antarctic Boundaries for IPY 2007-2009 from Satellite Radar, Version 2, Coastline Antarctica, NASA National Snow and Ice Data Center Distributed Active Archive Center [data set], Boulder, Colorado USA, https://doi.org/10.5067/AXE4121732AD, 2017

Ólason, E., Rampal, P., and Dansereau, V.: On the statistical properties of sea-ice lead fraction and heat fluxes in the Arctic, The Cryosphere, 15, 1053-1064, https://doi.org/10.5194/tc-15-10532021, 2021.

Perovich, D. K.: The optical properties of sea ice, Tech. rep., Cold Regions Research And Engineering Lab, Hanover, NH, USA, 1996.

Petty, A., Bagnardi, M., Kurtz, N., Tilling, R., Fons, S., Armitage, T., Horvat, C., and Kwok, R.: Assessment of ICESat2 Sea Ice Surface Classification with Sentinel-2 Imagery: Implications for Freeboard and New Estimates of Lead and Floe Geometry, Earth Space Sci., 8, e2020EA001491, https://doi.org/10.1029/2020EA001491, 2021.

Qu, M., Pang, X., Zhao, X., Zhang, J., Ji, Q., and Fan, P.: Estimation of turbulent heat flux over leads using satellite thermal images, The Cryosphere, 13, 1565-1582, https://doi.org/10.5194/tc-131565-2019, 2019.

Rampal, P., Dansereau, V., Olason, E., Bouillon, S., Williams, T., Korosov, A., and Samaké, A.: On the multi-fractal scaling properties of sea ice deformation, The Cryosphere, 13, 2457-2474, https://doi.org/10.5194/tc-13-2457-2019, 2019.

Reiser, F., Willmes, S., and Heinemann, G.: A New Algorithm for Daily Sea Ice Lead Identification in the Arctic and Antarctic Winter from Thermal-Infrared Satellite Imagery, Remote Sens., 12, 1957, https://doi.org/10.3390/rs12121957, 2020.

Rignot, E., Jacobs, S., Mouginot, J., and Scheuchl, B.: Iceshelf melting around Antarctica, Science, 341, 266-270, https://doi.org/10.1126/science.1235798, 2013.

Stern, H. L. and Lindsay, R. W.: Spatial scaling of Arctic sea ice deformation, J. Geophys. Res.-Oceans, 114, C10017, https://doi.org/10.1029/2009JC005380, 2009.

Tetzlaff, A., Lüpkes, C., and Hartmann, J.: Aircraft-based observations of atmospheric boundary-layer modification over Arctic leads, Q. J. Roy. Meteor. Soc., 141, 2839-2856, https://doi.org/10.1002/qj.2568, 2015.

Wadhams, P.: Sea-ice topography of the Arctic Ocean in the region $70 \mathrm{~W}$ to $25 \mathrm{E}$, Phil. Trans. R. Soc. Lond. A, 302, 45-85, https://doi.org/10.1098/rsta.1981.0157, 1981.

Wadhams, P., McLaren, A. S., and Weintraub, R.: Ice thickness distribution in Davis Strait in February from subma- 
rine sonar profiles, J. Geophys. Res.-Oceans, 90, 1069-1077, https://doi.org/10.1029/JC090iC01p01069, 1985.

Wang, Q., Danilov, S., Jung, T., Kaleschke, L., and Wernecke, A.: Sea ice leads in the Arctic Ocean: Model assessment, interannual variability and trends, Geophys. Res. Lett., 43, 7019-7027, https://doi.org/10.1002/2016GL068696, 2016.

Wernecke, A. and Kaleschke, L.: Lead detection in Arctic sea ice from CryoSat-2: quality assessment, lead area fraction and width distribution, The Cryosphere, 9, 1955-1968, https://doi.org/10.5194/tc-9-1955-2015, 2015.

Willmes, S. and Heinemann, G.: Sea-ice wintertime lead frequencies and regional characteristics in the Arctic, 2003-2015, Remote Sens., 8, 4, https://doi.org/10.3390/rs8010004, 2016.
WMO: WMO Sea Ice Nomenclature (WMO No. 259, volume 1 - Terminology and Codes, Volume II - Illustrated Glossary and III - International System of Sea-Ice Symbols), available at: https://library.wmo.int/index.php?lvl=notice_display\& id=6772\#.YNCOUf5CSUk (last access: 21 July 2021), 2014.

Worby, A. P., Geiger, C. A., Paget, M. J., Van Woert, M. L., Ackley, S. F., and DeLiberty, T. L.: Thickness distribution of Antarctic sea ice, J. Geophys. Res.-Oceans, 113, C05S92, https://doi.org/10.1029/2007JC004254, 2008. 